\title{
Synthesis and phosphatase activity of a Cobalt(II) phenanthroline complex
}

\author{
MAMONI GARAI ${ }^{\mathrm{a}}$, DHANANJAY DEY ${ }^{\mathrm{a}}$, HARE RAM YADAV $^{\mathrm{b}}$, MILAN MAJI $^{\mathrm{c}}$, \\ ANGSHUMAN ROY CHOUDHURY ${ }^{\mathrm{b}}$ and BHASKAR BISWAS ${ }^{\mathrm{a}, \mathrm{d}, *}$

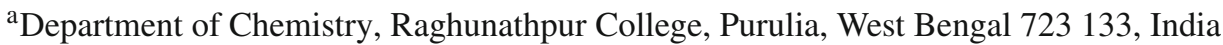 \\ ${ }^{b}$ Department of Chemical Sciences, Indian Institute of Science Education and Research Mohali, Sector 81, \\ S. A. S. Nagar, Manauli, P.O., Mohali, Punjab 140 306, India \\ ${ }^{\mathrm{c}}$ Department of Chemistry, National Institute of Technology, Mahatma Gandhi Avenue, Durgapur, \\ West Bengal 713 209, India \\ ${ }^{\mathrm{d}}$ Present Address: Department of Chemistry, Surendranath College, 24/2 Mahatma Gandhi Road, Kolkata, \\ West Bengal 700 009, India \\ E-mail: mr.bbiswas@rediffmail.com; icbbiswas@gmail.com
}

MS received 22 January 2017; revised 10 July 2017; accepted 13 July 2017; published online 19 September 2017

\begin{abstract}
A mononuclear cobalt(II) complex, $\left[\mathrm{Co}(\text { phen })_{2} \mathrm{Cl}_{2}\right]$, (phen $=1,10$-phenanthroline) has been synthesized and structurally characterized by different spectroscopic methods including single crystal X-ray structural study. X-ray crystal structural analysis revealed that the cobalt(II) complex crystallizes in a monoclinic system with $C 2 / c$ space group and exists in cis-configuration in its crystalline state. Room temperature magnetic measurement accounts for 3e paramagnetism and indicates high spin cobalt(II) in the solid state. The cobalt(II) complex has been evaluated as a functional model for phosphatase enzyme by using 4-nitrophenylphosphate (PNPP) as a standard substrate in aqueous DMF medium. This mononuclear cobalt(II) complex exhibits good hydrolytic phosphoester cleavage efficiency with $k_{\text {cat }}$ value of $3.78 \times 10^{2} \mathrm{~h}^{-1}$.
\end{abstract}

Keywords. Cobalt(II); 1,10-phenanthroline; crystal structure; supramolecular interactions; phosphatase activity.

\section{Introduction}

Designed coordination molecules with an ability to mimic the active sites of several bio-enzymes in an effective manner can lead to efficient bio-inspired catalysts having laboratory and industrial uses. ${ }^{1-3}$ Cobalt is an essential bio-element and found in cobalamin and in a few other metallo-proteins. ${ }^{4}$ Cobalamin is necessary for the formation of myelin, an insulating layer found around nerves, supporting the production of red blood cell, for the metabolism of fats and carbohydrates, and in the synthesis of proteins. ${ }^{4}$ Cobalt complexes containing polypyridyl ligand have several appealing structural and chemical properties in biological systems, as therapeutic agents and for drug design. 5,6 Cobalt(II) complexes are interesting for their capability to bind dioxygen reversibly ${ }^{7-9}$ and for their catalytic applicability in different oxidation reactions, ${ }^{10-13}$ in particular for the oxidation of phenols, alcohols, flavonoides, nitroalkanes, hydrazines or olefins. ${ }^{14-16}$ In addition, cobalt complexes have gained importance because of their application as potential hypoxia-activated prodrugs. ${ }^{17}$ Phosphoesterase enzyme in biological systems plays a vital role in the functioning DNA fragmentation, RNA replication, bone metabolism, chemotherapy and bio-remediation of organophosphate pesticides. ${ }^{18}$ The active site of the phosphoesterase enzyme typically consists of zinc ion and the metal centre is surrounded by $\mathrm{N}$ linkages from histidine ligands or $\mathrm{O}$ coordination from an aspartate, and often with bridging hydroxide ion. ${ }^{19}$ Although a similar complex has been reported by Hazell et al., ${ }^{20}$ we have produced this $\mathrm{Co}$ (II) complex following a different methodology. In our previous work, we have also investigated

\footnotetext{
*For correspondence
}

Electronic supplementary material: The online version of this article (doi:10.1007/s12039-017-1355-6) contains supplementary material, which is available to authorized users. 
the biological activity of $\left[\mathrm{Co}(\text { phen })_{2} \mathrm{Cl}_{2}\right]\left(\mathrm{NO}_{3}\right) \cdot \mathrm{xH}_{2} \mathrm{O}$ including anticancer activity. ${ }^{5 \mathrm{~b}}$ Herein, we report an octahedral mononuclear cobalt(II) phenanthroline complex, $\left[\mathrm{Co}(\text { phen })_{2} \mathrm{Cl}_{2}\right]$ (1) with X-ray crystal structure and its hydrolytic cleavage ability of phosphoester bond towards sodium salt of 4-nitrophenylphosphate (pNPP) with good turnover number, $k_{\text {cat }}=3.78 \times 10^{2} \mathrm{~h}^{-1}$ in aqueous DMF medium.

\section{Experimental}

\subsection{Materials}

High purity 1,10-phenanthroline (Lancaster, UK), cobalt(II) chloride hexahydrate, sodium azide, and glacial acetic acid (E. Merck, India) were purchased and used as received. All the other reagents and solvents are of Analytical grade (A.R. grade) and were purchased from commercial sources and used as received.

\subsection{Synthesis of $\left[\mathrm{Co}(\text { phen })_{2} \mathrm{Cl}_{2}\right](\mathbf{1})$}

$\mathrm{NaN}_{3}$ solution $(0.76 \mathrm{~g}, 1 \mathrm{mM})$ was added drop by drop to a solution of $\mathrm{CoCl}_{2} \cdot 6 \mathrm{H}_{2} \mathrm{O}(0.237 \mathrm{~g}, 1 \mathrm{mM})$ in the same solvent $(20 \mathrm{~mL})$ followed by the addition of 1,10 -phenanthroline $(0.360 \mathrm{~g}, 2 \mathrm{mmol})$ in $\mathrm{H}_{2} \mathrm{O}(10 \mathrm{~mL})$ and the resulting solution was kept in reflux for $3 \mathrm{~h}$. The solution was filtered and kept in air for slow evaporation. After 12-15 days the fine microcrystalline product was separated by decantation, washed with $\mathrm{n}$-hexane and dried in vacuo over silica gel indicator. Yield: $0.167 \mathrm{~g}(\sim 71 \%)$. Anal. Calc. for $\mathrm{C}_{20} \mathrm{H}_{20} \mathrm{~N}_{4} \mathrm{Cl}_{2} \mathrm{Co}$ : C58.80, $\mathrm{H}$ 3.29, N 11.43\%. Found: C 58.84, H 3.25, N 11.49\%. Selected IR bands (KBr pellet, $\left.\mathrm{cm}^{-1}\right)$ : 1636(s), 1605(s), UV-Vis $(\lambda$, $\mathrm{nm}, 10^{-4} \mathrm{M}, 1 \mathrm{~cm}$ optical pathlength, abs, aqueous medium): 240-270 (2.30), 353 (0.4384), 530-600 (0.0145); ESI-MS $\left(\mathrm{H}_{2} \mathrm{O}\right): \mathrm{m} / \mathrm{z}, 438.68$ (Calc. 438.08).

\subsection{Physical measurements}

Infrared spectrum $(\mathrm{KBr})$ was recorded with a FTIR-8400S SHIMADZU spectrophotometer in the range $400-3600 \mathrm{~cm}^{-1}$. ${ }^{1} \mathrm{H}$ NMR spectrum in DMSO- $d_{6}$ was obtained on a Bruker Avance $300 \mathrm{MHz}$ spectrometer at $25^{\circ} \mathrm{C}$ and was recorded at $299.948 \mathrm{MHz}$. Ground state absorption was measured with a JASCO V-730 UV-Vis spectrophotometer. Elemental analyses were performed on a Perkin Elmer $2400 \mathrm{CHN}$ microanalyser. Electrospray ionization (ESI) mass spectrum was recorded using a Q-tof-micro quadruple mass spectrometer. A Gouy balance was used to determine the magnetic susceptibility of the powdered sample, employing $\mathrm{Hg}(\mathrm{II})$ tetrathiocyanatocobaltate(II) as a calibrant. Diamagnetic corrections were made from the Pascal's constants. The Electron Paramagnetic Resonance (EPR) spectrum was recorded on a Bruker EMX-X band spectrometer (Model: EMX).

\subsection{Crystal structure determination and refinement}

Single crystal X-ray diffraction data were collected using a Rigaku XtaLABmini diffractometer equipped with Mercury375R $(2 \times 2$ bin mode $) \mathrm{CCD}$ detector. The data were collected with graphite monochromated Mo-K $\alpha$ radiation ( $\lambda=0.71073 \AA$ ) at $100.0(2) \mathrm{K}$ using $\omega$ scans. The data were reduced using Crystal Clear suite, and the space group determination was done using $\mathrm{Olex}^{2}$. The structure was resolved by direct method and refined by full-matrix least-squares procedures using the SHELXL-97 software package using OLEX ${ }^{2}$ suite. ${ }^{21,22}$

\subsection{Phosphatase activity of $\left[\mathrm{Co}(\text { phen })_{2} \mathrm{Cl}_{2}\right](1)$}

To examine the nature of hydrolytic cleavage of phosphoester bond by $\left[\mathrm{Co}(\mathrm{phen})_{2} \mathrm{Cl}_{2}\right]$ in aqueous DMF medium we have used disodium salt of (4-nitrophenyl)phosphate (PNPP) as a standard substrate following a previously reported procedure. ${ }^{23}$ The hydrolysis rate of PNPP in the presence of the cobalt complex was measured by an initial rate method keeping fixed the incremental band intensity in absorption at $416 \mathrm{~nm}$ due to the released p-nitrophenolate ion in aqueous $\mathrm{DMF}$ at $25^{\circ} \mathrm{C}$. For the wavelength scan, the spectrum was recorded by mixing a solution containing $1 \times 10^{-4} \mathrm{M}$ PNPP and $1 \times 10^{-2} \mathrm{M}$ cobalt(II) complex for $2 \mathrm{~h}$.

Kinetics experiments of the phosphoester cleavage of PNPP were performed by monitoring the growth of the 4nitrphenolate band at $416 \mathrm{~nm}$ as a function of time under the condition of excess substrate in presence of $\mathrm{Co}$ (II) complex, keeping the other parameters constant. Kinetic experiment was performed with 1 (at a constant concentration of $1 \times$ $10^{-4} \mathrm{M}$ ) and PNPP (varying the concentration from $1 \times 10^{-3}$ to $1 \times 10^{-2} \mathrm{M}$ ) in aqueous DMF using UV-Vis spectrophotometer. The visible absorption increase was recorded for a total period of $2 \mathrm{~h}$ at $9 \mathrm{~min}$ intervals. All the measurements were performed in triplicate.

\section{Results and Discussion}

\subsection{Synthesis and proposed mechanism for the preparation of the cobalt(II) complex}

$\left.[\mathrm{Co} \text { (phen })_{2} \mathrm{Cl}_{2}\right]$ was prepared by slow addition of aqueous solution of $\mathrm{NaN}_{3}$ to $\mathrm{CoCl}_{2}$ in the same solvent followed by the addition of aqueous solution of phenanthroline. Our aim was to prepare a cobalt compound containing phenanthroline and azide ligands by such reaction methodology. But we produced a cobalt(II) complex containing phenanthroline ligand and it is poorly soluble in all the common solvents like methanol, acetonitrile, water, etc.

To investigate the mechanistic pathway behind the formation of such $\mathrm{Co}$ (II) complex as the major product, we observed that $\mathrm{NaN}_{3}$ helped to create a reducing 


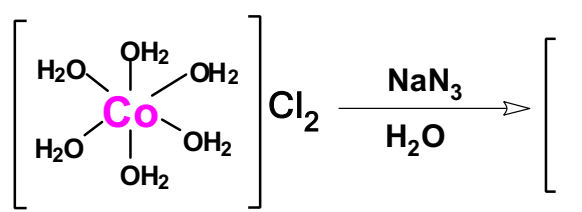
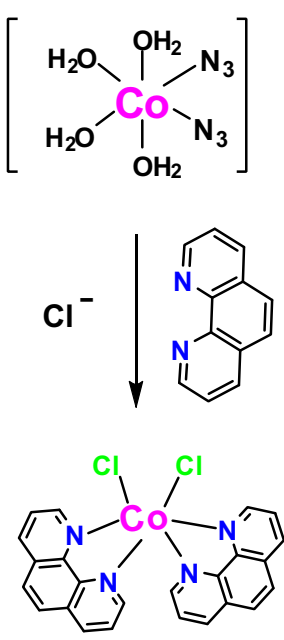

Scheme 1. Proposed mechanism for synthesis of Co(II) complex.

environment in the reaction mixture. ${ }^{24}$ At the primary stage of the reaction the pale pink solution of the $\mathrm{Co}$ (II) salt turned instantly brown during the addition of azide and indicated the incorporation of the azide ions into the coordination sphere of $\mathrm{Co}$ (II) centre with the displacement of chloride ions. At refluxing condition in presence of trace amount of glacial acetic acid, Co(II) centre kept itself stabilized in its lower oxidation state and complexation occurred with 1,10-phenanthroline ( $\pi$-acidic ligand), which is known as a good stabilizer ${ }^{25}$ for metal ions having lower oxidation states. The chloride ions which get displaced at the primary stage may now act as a better nucleophile than water molecule and forms a cis-dichloro bis(phenanthroline) cobalt(II) complex. Controlled experiments under the same conditions in the absence of $\mathrm{NaN}_{3}$ revealed that for successful production of this cobalt(II)-phen complex, sodium azide is essential (Scheme 1). We used this reaction methodology previously in the preparation of an oxido-bridged diiron(II)-phenanthroline compound. ${ }^{24}$

\subsection{Crystal structure}

The molecular structure of $\left[\mathrm{Co}(\text { phen })_{2} \mathrm{Cl}_{2}\right](\mathbf{1})$ is shown in Figure 1, while the structural refinement parameters are given in Table 1. Selected bond lengths and angles are listed in Table S1 (in Supplementary Information). According to the X-ray data, the complex crystallizes in the monoclinic system with $C 2 / \mathrm{c}$ space group. The coordination geometry around the $\mathrm{Co}$ (II) centre is best described as a distorted octahedron with a $\mathrm{CoN}_{4} \mathrm{Cl}_{2}$ coordination core formed by four nitrogen atoms of two bidentate phenanthroline ligands and two chlorine atoms (Figure 1). The $\mathrm{Cl}(2)-\mathrm{Co}(1)-\mathrm{Cl}(2 *)$

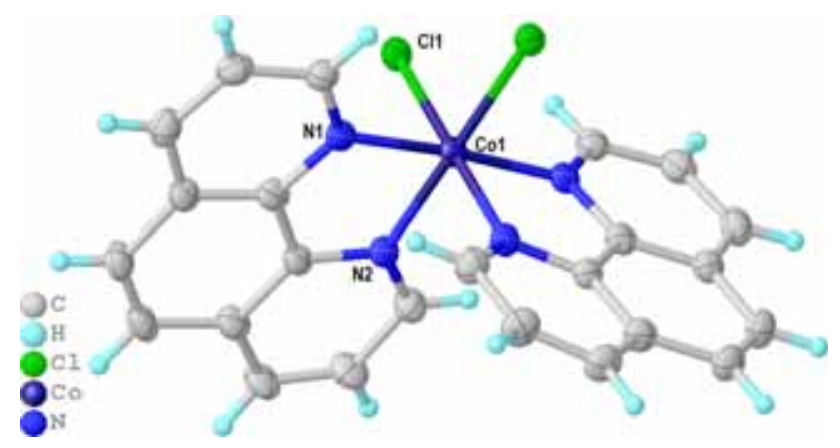

Figure 1. Thermal ellipsoid (30\%) plot of the cation of $\left[\mathrm{Co}(\text { phen })_{2} \mathrm{Cl}_{2}\right](\mathbf{1})$.

Table 1. Crystallographic data of $\left[\mathrm{Co}(\text { phen })_{2} \mathrm{Cl}_{2}\right](\mathbf{1})$.

\begin{tabular}{lc}
\hline Parameters & $\mathrm{Co}(\mathrm{II})$ compound \\
\hline Empirical formula & $\mathrm{C}_{24} \mathrm{H}_{16} \mathrm{~N}_{4} \mathrm{Cl}_{2} \mathrm{Co}$ \\
Formula weight & 490.24 \\
Temperature $(\mathrm{K})$ & $100.0(2)$ \\
Crystal system & Monoclinic \\
Space group & $\mathrm{C} 2 / \mathrm{c}$ \\
$\mathrm{a}(\AA)$ & $15.3582(7)$ \\
$\mathrm{b}(\AA)$ & $13.0120(6)$ \\
$\mathrm{c}(\AA)$ & $13.1966(7)$ \\
Volume $\left(\AA^{3}\right)$ & $2582.7(2)$ \\
$\mathrm{Z}$ & 4 \\
$\rho\left(\mathrm{gcm}^{-3}\right)$ & 1.261 \\
$\mu\left(\mathrm{mm}^{-1}\right)$ & 0.887 \\
$\mathrm{~F}(000)$ & 996 \\
$\theta$ ranges $\left({ }^{\circ}\right)$ & $2.7-32.8$ \\
$\left.\mathrm{R}_{\text {int }}\right)$ & 0.038 \\
$\mathrm{R}(\mathrm{reflections})$ & 15618 \\
$w R 2($ reflections $)$ & 4565 \\
Final R indices & $0.0593,0.1862$ \\
Largest peak and hole $\left(\mathrm{eA}^{\circ-3}\right)$ & $1.54,-0.74$ \\
\hline
\end{tabular}

angle $\left(91.61^{\circ}\right)$ indicates the cis conformation of the structure. Though there is a possibility to exist in cisand trans-form of the Co-phen complex, but lower solubility of the cis- conformation accounts for the primary isolation of cis-[Co(phen $\left.)_{2} \mathrm{Cl}_{2}\right]$ in the form of single crystals. In solid state, adjacent complex units, $\left[\mathrm{Co}(\mathrm{phen})_{2} \mathrm{Cl}_{2}\right]$ are interlinked to form an interpenetrating 3D supramolecular architecture through a number of $\mathrm{C}-\mathrm{H} \cdots \mathrm{Cl}$ intermolecular hydrogen bonds (Figure 2). In the construction of 3D superstructure through strong intermolecular $\mathrm{H}$-bonding interactions $(\mathrm{C} 2-\mathrm{H} 2 \ldots \mathrm{Cl} 1$,

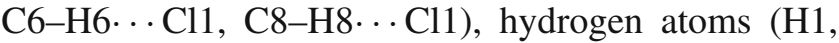
$\mathrm{H} 6, \mathrm{H} 8, \mathrm{H} 10)$ attached to aromatic carbon atoms act as acceptors while chlorine atom (Cl1) coordinated to cobalt(II) centre behave as donor centre. The values of $\mathrm{H} \cdots \mathrm{Cl}$ supramolecular interactions remain very close to $\sim 2.8 \AA$ which are weak but acceptable in 


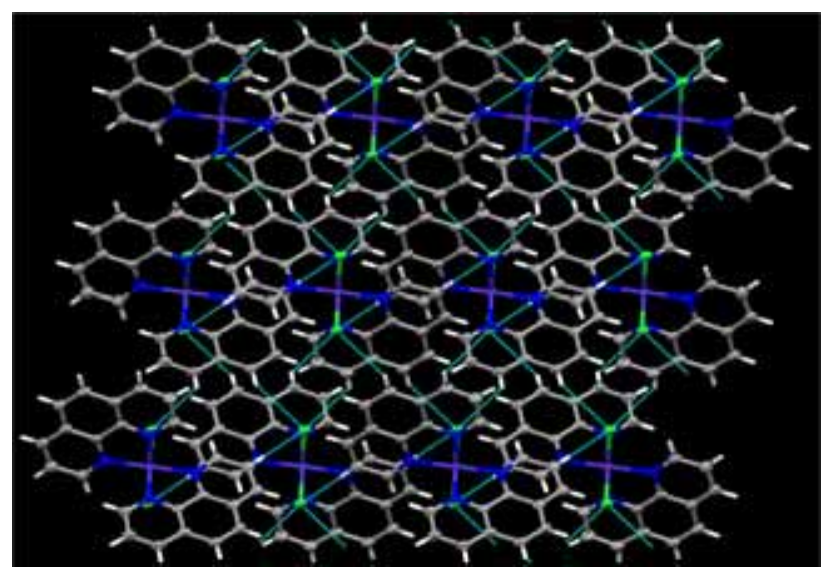

Figure 2. Formation of 3D crystalline architecture through intermolecular $\mathrm{H}$...Cl hydrogen bonds in $\left[\mathrm{Co}(\mathrm{phen})_{2} \mathrm{Cl}_{2}\right]$ (1).

scientific literature ${ }^{5 b, 6 a}$ on the perspective of $\mathrm{H} \cdots \mathrm{Cl}$ interactions. The details of $\mathrm{C}-\mathrm{H} \cdots \mathrm{Cl}$ intermolecular hydrogen bonds are given in Table S2 (in Supplementary Information) (Figure 2).

\subsection{Electronic spin and solution properties}

Cobalt(II) complexes exhibit interesting magnetic susceptibility at room temperature and low temperature, and often displays spin-state transition phenomenon. ${ }^{26-30}$ We find room temperature magnetic susceptibility value, $\mu_{\mathrm{eff}}=4.78 \mu \mathrm{B}$ for this cobalt(II) octahedral compound in solid state and this magnetic susceptibility value is larger than the spin-only value expected for a high spin $d^{7}$ ion $(S=3 / 2,3.87 \mu B)$. This accounts for the presence of three unpaired electrons in solid state at room temperature. We have also performed EPR analysis at RT and LT $(77 \mathrm{~K})$ using single crystals of this cobalt compound but the spectrum remained silent in both phases. Now, in general high-spin octahedral cobalt(II) ion has a ${ }^{4} \mathrm{~T}_{1 \mathrm{~g}}$ ground state. The magnetic moments of cobalt(II) complexes with $\mathrm{T}$ ground terms are often found to show considerable temperature dependence, and interpreting them is very difficult because the angular orbital momentum is partially quenched. ${ }^{26,27}$ Due to large spin-orbit coupling, these systems exhibit substantial zero field splitting, which causes high magnetic anisotropy ${ }^{28-30}$ and causes very strong spin lattice relaxation time for the high spin cobalt(II) complexes. ${ }^{29}$ In general, few cobalt complexes which show EPR signal at RT/LT were low spin cobalt complexes like cobalt-phthalocyanine of square planar geometry. Literature survey indicates, high spin pure cobalt(II) compounds in octahedral geometry give rise to valuable information only at

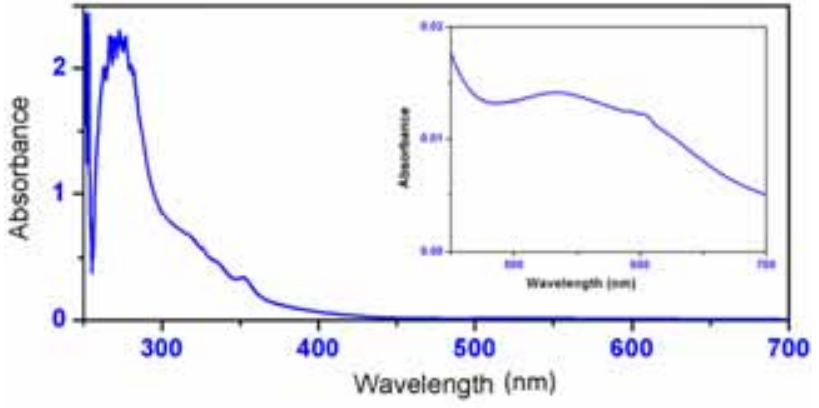

Figure 3. UV-Vis spectrum of $\left[\mathrm{Co}(\text { phen })_{2} \mathrm{Cl}_{2}\right](\mathbf{1})$ in water. Inset Expansion of UV-Vis spectrum of $\mathbf{1}$ from 450 to $700 \mathrm{~nm}$ in water medium $\left[10^{-4} \mathrm{M}, 1 \mathrm{~cm}\right.$ optical path length].

liquid helium temperature $(4 \mathrm{~K})$ but variable temperature magnetic measurement may lead to more insight about the electronic spin nature of this cobalt(II)phenanthroline complex. ${ }^{26-30}$

We have made a comparison between the spectral profiles of the reported octahedral cobalt(II) compound and our compound which reveals the spin configuration of our cobalt(II) compound in solution phase. The interpretation of the visible spectra for the octahedral cobalt(II) is still difficult in spite of existence of a large number of cobalt(II) compounds. ${ }^{31}$ The origin of visible spectra for cobalt(II) compounds may be due to spin-orbit coupling, vibrational or low symmetry components, and contribution of these parameters bring difficulties in the total spectral analyses of sixcoordinated cobalt(II) complexes. ${ }^{31}$ Kundu et al., ${ }^{32}$ showed that an octahedral cobalt(II) compound having $\mathrm{CoN}_{4} \mathrm{O}_{2}$ chromophore exhibits a distinct absorption band at $521 \mathrm{~nm}$ which corresponds to the high spin octahedral cobalt(II) environment. Kapoor et al., ${ }^{33}$ produced a series of octahedral cobalt(II) compounds and found broad absorption band at $\sim 550 \mathrm{~nm}$. Handel et al., ${ }^{34}$ observed absorption band at $\sim 480 \mathrm{~nm}$ for cobalt(II) compounds containing tridentate N-donor Schiff base ligand and inferred in favour of octahedral high spin cobalt(II) compounds. Herein, in our absorption spectrum (Figure 3 ) in aqueous medium, we observed three characteristic spectral bands: 240-270, 353, 530$600 \mathrm{~nm}$ (very broad). Among the three bands, two strong transitions in the UV region are of ligand centered and assigned to $\pi-\pi^{*}$ on $n-\pi *$ transitions in the pyridine rings of phenanthroline ligand. A weaker broad absorption band $\sim 550 \mathrm{~nm}$ was observed in aqueous medium and assignable to ${ }^{4} \mathrm{~T}_{1 \mathrm{~g}}(\mathrm{~F}) \rightarrow{ }^{4} \mathrm{~T}_{1 \mathrm{~g}}(\mathrm{P})$ electronic transition which is a characteristic of high spin octahedral cobalt(II) environment. Electron spray ionization mass spectral study was also performed which confirmed the molecular existence of the cobalt(II) compound in 


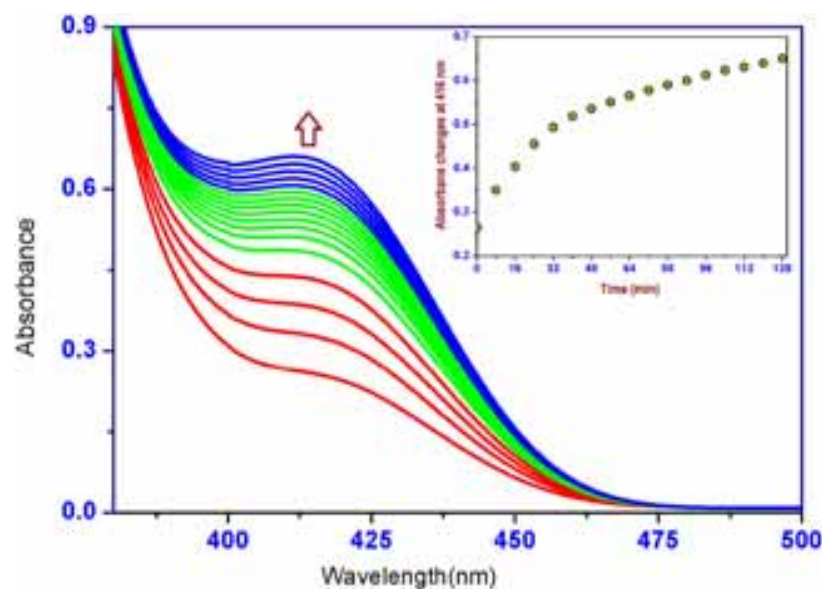

Figure 4. Increase of 4-nitrophenolate band at $423 \mathrm{~nm}$ after addition of 100 equivalents of PNPP to $\left[\mathrm{Co}(\text { phen })_{2} \mathrm{Cl}_{2}\right](\mathbf{1})$ solution in aq. DMF medium. The spectra were recorded after every $9 \mathrm{~min}$.

aqueous medium: ESI-MS $\left(\mathrm{H}_{2} \mathrm{O}\right): \mathrm{m} / \mathrm{z}, 438.68$ (Calc. 438.08).

\subsection{Phosphatase activity of $\left[\mathrm{Co}(\text { phen })_{2} \mathrm{Cl}_{2}\right](1)$ and its mechanistic implications}

We have followed the changes in the spectral features of the $\mathrm{Co}$ (II)-phen complex upon the addition of PNPP using spectrophotometrically and the observations are shown in Figure 4, where the spectra were recorded for $2 \mathrm{~h}$ at $9 \mathrm{~min}$ intervals. In order to examine the hydrolytic cleavage efficiency of phosphoester bonds in aqueous DMF, we have monitored the time evolution of 4nitrophenolate $\left(\lambda_{\max }=416 \mathrm{~nm}\right)$ through a wavelength scan from 200 to $900 \mathrm{~nm}$ at $25^{\circ} \mathrm{C}$, containing 100 equivalents of substrate relative to the catalyst, until roughly $2 \%$ reaction conversion was reached.

The kinetics study was performed using the initial slope method, following the rate of increase in the absorption of the band at $416 \mathrm{~nm}$ corresponding to a rise of 4-nitrophenolate concentration. The initial first order rate constant, $k_{\text {obs }}\left(\mathrm{min}^{-1}\right)=5.78 \times 10^{-4}($ Error $=$ $\left.4.90 \times 10^{-5}\right)$ for the cleavage of PNPP was obtained from the plot of $\log \left[\mathrm{A}_{\alpha} /\left(\mathrm{A}_{\alpha}-\mathrm{A}_{\mathrm{t}}\right)\right]$ versus time (Figure 5) which was linear with $\mathrm{R}^{2}=0.9519$. The kinetic parameters $\left(\mathrm{V}_{\max }, \mathrm{k}_{\mathrm{M}}, k_{\mathrm{cat}}\right)$ for the catalyzed reactions were determined by applying Michaelis-Menten eq. for enzymatic kinetics and found as follows: $\mathrm{V}_{\max }=1.055 \times$ $10^{-4}\left( \pm 1.98 \times 10^{-5}\right), \mathrm{k}_{\mathrm{M}}=4.27 \times 10^{-3}\left( \pm 1.21 \times 10^{-4}\right)$ (Figure S2 in Supplementary Information). Turn over number for this hydrolytic catalysis was determined as $k_{\text {cat }}=3.78 \times 10^{2} \mathrm{~h}^{-1}$. To confirm the non-catalytic properties of the ligand, control experiments were performed

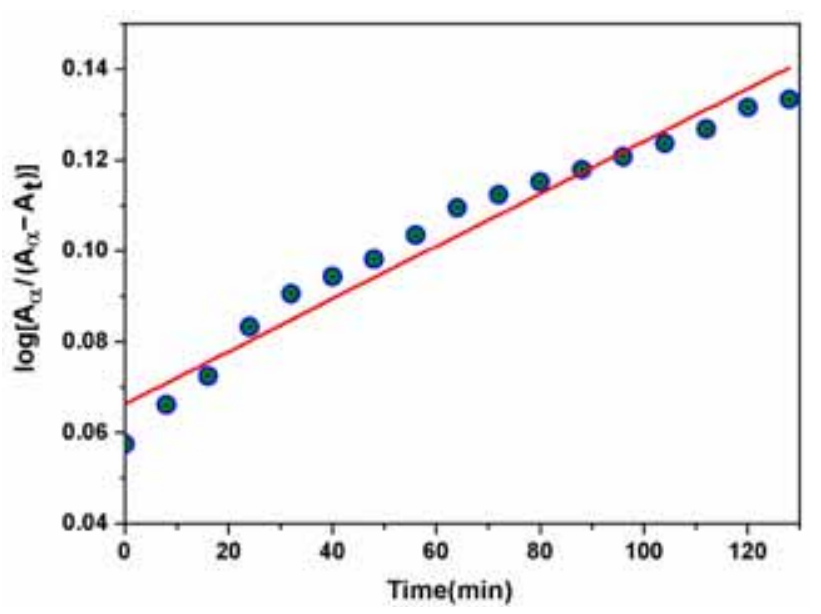

Figure 5. Initial rate determination using plot of $\log \left[\mathrm{A}_{\alpha} /\left(\mathrm{A}_{\alpha}-\mathrm{A}_{\mathrm{t}}\right)\right]$ versus time.

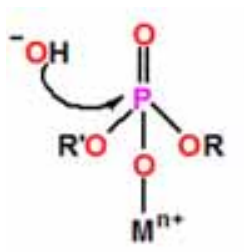

Lewis acid Activation

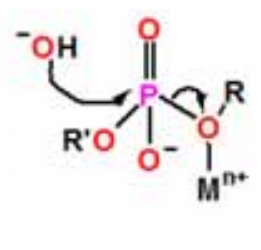

Leaving group Activation

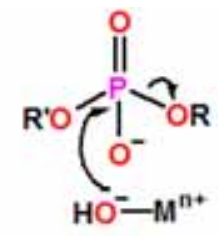

metal-nucleophile

Activation
Scheme 2. Modes by which phosphates are activated by metal ions.

and found to be non-responsive towards PNPP hydrolysis.

We have taken careful measure to propose the cleavage mechanism of PNPP for our cobalt(II) complex from the reported scientific literature. ${ }^{35-39}$ It is seen that metal catalysts can take significant initiative for catalytic cleavage of PNPP through Lewis acid activation, metal-nucleophile attack and leaving group activation (Scheme 2), and exhibit remarkably fast rates of phosphate hydrolysis. Rate of acceleration for the catalytic phenomenon is observed when multiple assisting parameters are working concurrently. ${ }^{35-38}$ After rigorous review of the scientific literature, herein, we propose the plausible catalytic cycle having reasonably good agreement with our kinetic result. The generation of nucleophile from coordinated water molecules at the metal centres in the reaction medium remains the fundamental aspect in this catalysis which later follows the attack of metal bound nucleophile on phosphorous atom, as a representative mechanism (Scheme 3).

In aqueous DMF solution, metal coordinated nitrate ion gets dissociated from Co(II)-phen complex. Here, in solution, metal coordinated water molecule plays the most significant role to facilitate hydrolytic cleavage 


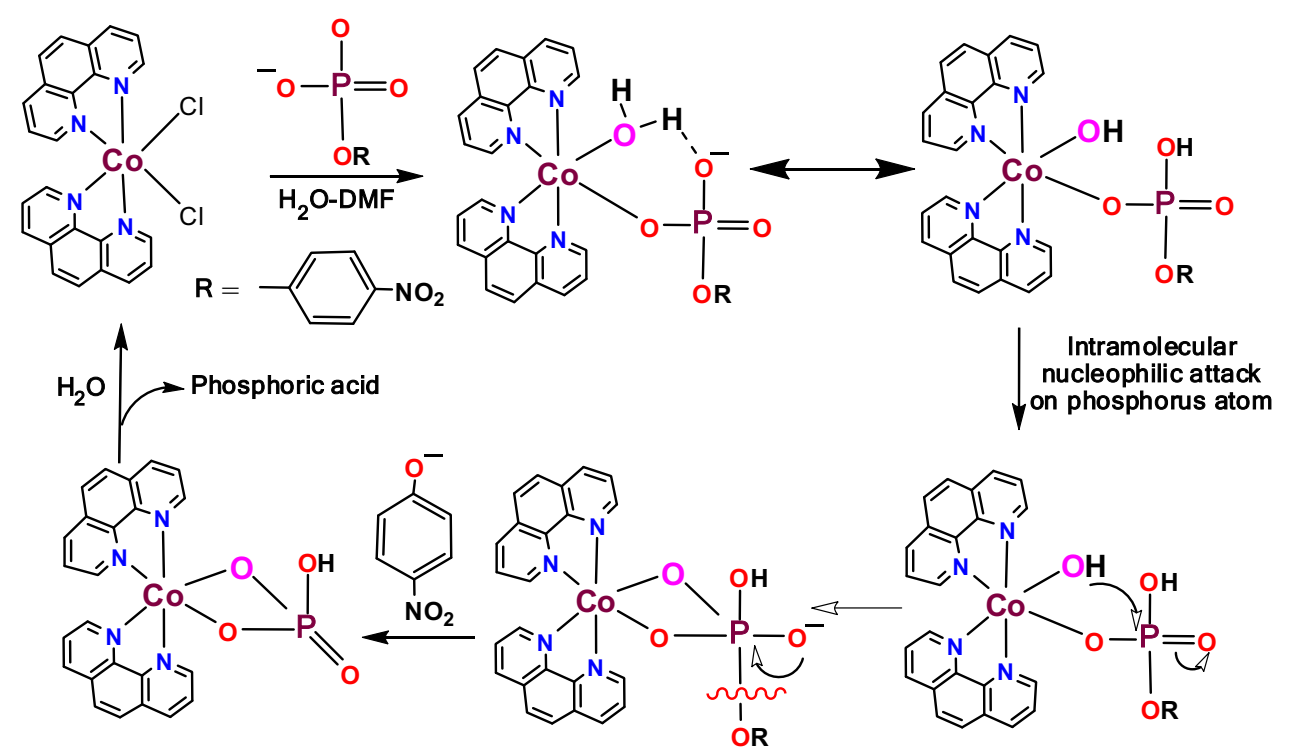

Scheme 3. Plausible mechanistic pathway for PNPP hydrolysis promoted by Co(II)-phen complex.

of PNPP. Addition of PNPP to Co(II)-phen complex occurred in a monodentate fashion which is further established probably through $\mathrm{O} \cdots \mathrm{H}$ interactions between anionic oxide ion with $\mathrm{H}$ atom of the coordinated water molecule. At this stage, the coordinated water molecule deprotonates to yield a hydroxide ion as the potent nucleophile leading to an intermediate which is further consolidated in ESI-MS study as a major signal at $\mathrm{m} / \mathrm{z}$ of 534.06 (Figure S3 in Supplementary Information). It is followed by the formation of an organophosphorus intermediate by nucleophilic substitution reaction with the concomitant expulsion of p-nitrophenolate ion. It then gradually breaks down into the original complex and phosphoric acid.

Phosphoesterase mimics by cobalt(II) complexes are not extensively studied and a few comparative studies of phosphoester cleavage is available in recent literature. ${ }^{40-43}$ Previous studies have suggested that the coordinated alcohol is deprotonated at higher $\mathrm{pH}$ or coordinated water molecule ${ }^{44}$ below the same $\mathrm{pH}$. Both the coordinated alcohol and water molecule act as effective nucleophiles. ${ }^{45,46}$ However, in our complex, solvent aqua molecules displaced the labile chloride ions and behaved as effective nucleophile towards phosphoester cleavage activity. ${ }^{44}$

\section{Conclusions}

Herein, we report a synthesis and structural characterization of a $\left[\mathrm{Co}(\mathrm{phen})_{2} \mathrm{Cl}_{2}\right]$ compound under $\mathrm{N}_{2}$ atmosphere. Room temperature magnetic susceptibility of this cobalt(II)-phenanthroline complex in powder state indicates the existence of three-electron high spin state. A comparison of UV-Vis spectrum between our cobalt(II) complex with other cobalt(II) complexes further confirm the spin state. The cobalt(II) complex has been evaluated as a functional model for phosphatase enzyme by using 4-nitrophenylphosphate (PNPP) as a standard substrate in aqueous DMF medium. This cobalt(II) complex exhibits good hydrolytic phosphoester cleavage efficiency and $k_{\text {cat }}$ value is $3.78 \times 10^{2} \mathrm{~h}^{-1}$.

\section{Supplementary Information (SI)}

Supplementary crystallographic data are available free of charge from The Director, CCDC, 12 Union Road, Cambridge, CB2 1EZ, UK (fax: +44-1223-336033; E-mail: deposit@ccdc.cam.ac.uk or www: http://www.ccdc.cam.ac. uk) upon request, quoting deposition number CCDC 1528654. FTIR, UV-Vis spectra, ESI-MS, rate vs concentration of PNPP, and table of crystallographic parameters are given in supplementary information, available at www.ias.ac.in/ chemsci.

\section{Acknowledgements}

BB gratefully acknowledges the Science \& Engineering Research Board (SERB), a statutory body under Department of Science and Technology (DST), New Delhi for financial support under the FAST TRACK SCHEME for YOUNG SCIENTIST (No. SB/FT/CS-088/2013 dtd. 21/05/2014). ARC and HRY thank IISER Mohali for XtaLab mini diffractometer facility. HRY thanks IISER Mohali for senior research fellowship. This research work is dedicated to Dr. Pradeepta Guptaray, Principal, Dum Dum Motijheel College, Kolkata 700 074, West Bengal, India for remaining a constant source of inspiration. 


\section{References}

1. (a) Hage R and Lienke A 2006 Applications of transitionmetal catalysts to textile and wood-pulp bleaching Angew. Chem. 118 212; (b) De A, Dey D, Yadav H R, Maji M, Rane V, Kadam R M, Choudhury A R and Biswas B 2016 Unprecedented hetero-geometric discrete copper(II) complexes: Crystal structure and biomimicking of Catecholase activity J. Chem. Sci. 128 1775

2. (a) Duran D and Esposito E 2000 Potential applications of oxidative enzymes and phenoloxidase-like compounds in wastewater and soil treatment: A review Appl. Catal. B 28 83; (b) Dey D, Kaur G, Ranjani A, Gyathri L, Chakraborty P, Adhikary J, Pasan J, Dhanasekaran D, Choudhury A R, Akbarsha M A, Kole N and Biswas B 2014 A trinuclear zinc-Schiff base complex: Biocatalytic activity and cytotoxicity Eur. J. Inorg. Chem. 3350

3. (a) Kaim W and Schwederski B 1993 Bioanorganische Chemie (Series: Teubner, Stuttgart) In Bioinorganic Catalysis J Reedijk (Ed.) (New York: Marcel Dekker); (b) Que L and Tolman W B 2008 Biologically inspired oxidation catalysis Nature 455333; (c) Pal S, Chowdhury B, Patra M, Maji M and Biswas B 2015 Ligand centered radical pathway in catechol oxidase activity with a trinuclear zinc-based model: Synthesis, structural characterization and luminescence properties Spectrochim. Acta Part A Mol. Biomol. Spect. 144148

4. (a) Trawick B N, Daniher A T and Bashkin J K 1998 Inorganic mimics of ribonucleases and ribozymes: From random cleavage to sequence-specific chemistry to catalytic antisense drugs. Chem. Rev. 98 939; (b) Ermens A A, Vlasveld L T and Lindemans J 2003 Significance of elevated cobalamin (vitamin B12) levels in blood 2003 Clin. Biochem. 36585

5. (a) Wang J, Yang M, Dong W, Jin Z, Tang J, Fan S, Lu Y and Wang G 2016 Co(II) complexes loaded into metalorganic frameworks as efficient heterogeneous catalysts for aerobic epoxidation of olefins Catal. Sci. Technol. 6 161; (b) Dey D, Basu Roy A, Shen C-Y, Tsai H-L, Ranjani A, Gayathri L, Chandraleka S, Dhanasekaran D, Akbarsha M A, Kole N and Biswas B 2015 Synthesis and bio-catalytic activity of isostructural cobalt(III)phenanthroline complexes J. Chem. Sci. 127649

6. (a) Das S, Pasan J, Gayathri L, Saha S, Chandraleka S, Maji M, Dhanasekaran D, Akbarsha M A, Kole $\mathrm{N}$ and Biswas B 2016 Recognition of self-assembled water-nitrate cluster in a $\mathrm{Co}$ (III)-2,2'-bipyridine host: Synthesis, crystal structure, DNA cleavage, molecular docking and anticancer activity J. Chem. Sci. 128 1755; (b) Dauma L J, Comba P, Larrabee J A, Schenk G, Stranger R, Cavigliasso G and Gahan L R 2013 Synthesis, magnetic properties, and phosphoesterase activity of dinuclear cobalt(II) complexes Inorg. Chem. 522029

7. Matsuura T 1977 Bio-mimetic oxygenation by cobalt complexes Tetrahedron 332869

8. Chen D and Martell A E 1987 Dioxygen affinities of synthetic cobalt Schiff base complexes Inorg. Chem. 26 1026

9. Busch D H and Alcock N W 1994 Iron and cobalt "lacunar" complexes as dioxygen carriers Chem. Rev. 94585
10. Singh A K and Mukherjee R 2008 Cobalt(II) and cobalt(III) complexes of thioether-containing hexadentate pyrazine amide ligands: $\mathrm{C}-\mathrm{S}$ bond cleavage and cyclometallation reaction Dalton Trans. 260

11. Wang F, Cao B, To W P, Tse C W, Li K, Chang X Y, Zang C, Chan S L F and Che C F 2016 The effects of chelating $\mathrm{N}_{4}$ ligand coordination on $\mathrm{Co}(\mathrm{II})$-catalysed photochemical conversion of $\mathrm{CO}_{2}$ to $\mathrm{CO}$ : Reaction mechanism and DFT calculations Catal. Sci. Technol. 67408

12. (a) Xin Zhang C, Liang H-C, Humphreys K J and Karlin K D 2003 In Advances in catalytic activation of dioxygen by metal complexes L I Simándi (Ed.) (Dordrecht: Kluwer Academic Publishers) Ch. 2 p. 79; (b) Simándi L I 2003 In Advances in catalytic activation of dioxygen by metal complexes L I Simándi (Ed.) (Dordrecht: Kluwer Academic Publishers) Ch. 6 p. 265

13. Sharma V B, Jain S L and Sain B 2004 Cobalt(II) Schiff base catalyzed aerobic oxidation of secondary alcohols to ketones J. Mol. Catal. A Chem. 21255

14. Sun B, Chen J, Hu J and Li X 2006 Dioxygen affinities and catalytic oxidation activities of cobalt complexes with Schiff bases containing crown ether J. Inorg. Biochem. 1001308

15. L Que, M F Reynolds, A Sigel and H Sigel (Eds.) 2000 In Metal ions in biological systems (New York: Marcel Dekker) Vol. 37, p. 505

16. (a) Nishinaga A and Funabiki T (Eds.) 1997 In Oxygenases and model systems (Dordrecht: Kluwer Academic Publishers) p. 157; (b) Wikaira J, Gorun S M, Reedijk J and Bouwman E (Eds.) 1999 In Bioinorganic catalysis (New York: Marcel Dekker) p. 355

17. (a) Funabiki T 1997 In Oxygenases and model systems T Funabiki (Ed.) (Dordrecht: Kluwer Academic Publishers) pp. 105-155; (b) T Funabiki and L I Simándi (Eds.) 2003 In Advances in catalytic activation of dioxygen by metal complexes (Dordrecht: Kluwer Academic Publishers) Ch. 4, p.157; (c) Blower P J, Dilworth J R, Maurer R I, Mullen G D, Reynolds C A and Zheng Y 2001 Towards new transition metal-based hypoxic selective agents for therapy and imaging Inorg. J. Biochem. 8515

18. (a) Uzunov $\mathrm{P}$ and Weiss B 1972 Separation of multiple molecular forms of cyclic adenosine- $3^{\prime}, 5^{\prime}$ monophosphate phosphodiesterase in rat cerebellum by polyacrylamide gel electrophoresis Biochim. Biophys. Acta (BBA) Enzymol. 284 220; (b) Hough E, Hansen L K, Birkens B, Jynge K, Hansen S, Hardvik A, Little C and Dodson Derewenda E Z 1989 High-resolution (1.5 $\AA$ ) crystal structure of phospholipase C from Bacillus cereus Nature 338357

19. Jeon Y H, Heo Y-S, Kim C M, Hyun Y-L, Lee T G, Ro S and Cho J M 2005 Phosphodiesterase: Overview of protein structures, potential therapeutic applications and recent progress in drug development Cell. Mol. Life Sci. 621198

20. Hazell A, Mcginley J and Mckenzie C J 1997 Dichlorobis(1,10-phenanthroline-N,N')cobalt(II)acetonitrile (1/1.5) Acta Crystallogr. C $\mathbf{5 3} 723$

21. CrystalClear 2.0; Rigaku Corporation: Tokyo, Japan

22. Sheldrick G M 2008 A short history of SHELX Acta Crystallorgr. A 64112

23. Sanyal R, Zhang X, Chakraborty P, Giri S, Chattopadhyay S K, Zhao C and Das D 2016 Role of solvent in the 
phosphatase activity of a dinuclear nickel(II) complex of a Schiff base ligand: Mechanistic interpretation by DFT studies New J. Chem. $\mathbf{4 0} 7388$

24. (a) Schollhorn R and Burris R H 1967 Biochemistry 57 1317; (b) Dey D, De A, Yadav H R, Guin P S, Roy Choudhury A, Kole $\mathrm{N}$ and Biswas B 2016 An oxo-bridged diiron(II) complex as functional model of catechol dioxygenase ChemistrySelect 01 1910

25. Bencini A and Lippolis V 2010 1,10-Phenanthroline: A versatile building block for the construction of ligands for various purposes Coord. Chem. Rev. 254 2096

26. Sakiyama H 2006 Magnetic susceptibility equation for dinuclear high-spin cobalt(II) complexes considering the exchange interaction between two axially distorted octahedral cobalt(II) ions Inorg. Chim. Acta 359 2097

27. Kahn O 1993 In Molecular magnetism (New York: VCH Publishers)

28. Ostrovsky S M, Werner R, Brown D A and Haase W 2002 Magnetic properties of dinuclear cobalt complexes Chem. Phys. Lett. 353290

29. Goodwin H A 2004 Spin crossover in cobalt(II) systems Top. Curr. Chem. 23423

30. Lloret F, Julve M, Cano J, Ruiz-Garcia R and Pardo E 2008 Magnetic properties of six-coordinated high-spin cobalt(II) complexes: Theoretical background and its application Inorg. Chim. Acta 3613432

31. Sole J G, Bausa L E and Jaque D 2005 In An introduction to the optical spectroscopy of inorganic solids (New York: Wiley)

32. Kundu S, Roy S, Bhar K, Ghosh R, Lin C -H, Ribas J and Ghosh B K 2013 Synthesis, molecular and crystalline architectures, and properties of a mononuclear complex $\left.\left[\mathrm{Co}^{\mathrm{II}} \text { (benzidine }\right)_{2}(\mathrm{NCS})_{2}\left(\mathrm{OH}_{2}\right)_{2}\right]$ J. Chem. Sci. 125723

33. Kappor R, Pathak A, Kapoor P and Venugopalan P 2006 Studies on cobalt(II) complexes with $N, N, N^{\prime}$, $N^{\prime}$-tetraethylpyridine-2,6-dicarboxamide $\left(\mathrm{L}^{1}\right)$ containing $\mathrm{PF}_{6}^{-} ; \mathrm{BF}_{4}^{-} ; \mathrm{ClO}_{4}^{-}$and $\mathrm{NO}_{3}^{-}$anions: X-ray crystal structures of $\left[\mathrm{Co}\left(\mathrm{L}^{1}\right)_{2}\left(\mathrm{CH}_{3} \mathrm{CN}\right)\right]\left(\mathrm{PF}_{6}\right)_{2}$ and $\left[\mathrm{Co}\left(\mathrm{L}^{1}\right)_{2}\left(\mathrm{H}_{2} \mathrm{O}\right)_{2}\right](\mathrm{X})_{2} . \mathrm{H}_{2} \mathrm{O}\left(\mathrm{X}=\mathrm{PF}_{6}^{-}, \mathrm{ClO}_{4}^{-}\right)$Polyhedron 2531

34. Handel R, Willms H, Jameson G B, Berry K J, Moubaraki B, Murray K S and Brooker S 2010 Factors influencing the structural and magnetic properties of octahedral cobalt(II) and iron(II) complexes of terdentate N3 schiff base ligands Eur. J. Inorg. Chem. 3317
35. Hendry P and Sargeson A M 1990 A structural and functional model of dinuclear metallophosphatases Inorg. Chem. 2992

36. Hendry P and Sargeson A M 1986 Base hydrolysis of coordinated trimethyl phosphate Aust. J. Chem. 391177

37. Benkovic S and Dunikoski L 1971 Unusual rate enhancement in metal ion catalysis of phosphate transfer J. Am. Chem. Soc. 931526

38. Fife T and Pujari M 1988 Divalent metal ion catalysis in the hydrolysis of phosphomonoesters. Hydrolysis of 2-(1,10-phenanthrolyl) phosphate J. Am. Chem. Soc. 110 7790

39. Williams N H, Takasaki B, Wall M and Chin J 1999 Structure and nuclease activity of simple dinuclear metal complexes: Quantitative dissection of the role of metal ions Acc. Chem. Res. 3248

40. Zhang Z, Yu X, Fong L K and Margerum L D 2001 Ligand effects on the phosphoesterase activity of $\mathrm{Co}$ (II) Schiff base complexes built on PAMAM dendrimers Inorg. Chim. Acta 31772

41. Jikido R, Shiraishi H, Matsufuji K, Ohba M, Furutachi H, Suzuki M and Okawa H 2005 Bull. Chem. Soc. Jpn. 781795

42. Zhang Z, Xie J-Q, Tang Y, Li J, Li J-Z, Zeng W and Hu C-W 2005 J. Chem. Res. 2130

43. Arora H, Barman S K, Lloret F, Mukherjee R 2012 Isostructural dinuclear phenoxo-/acetato-bridged manganese(II), cobalt(II), and zinc(II) complexes with labile sites: Kinetics of transesterification of 2-hydroxypropylp-nitrophenylphosphate Inorg. Chem. 515539

44. Bazzicalupi C, Bencini A, Berni E, Bianchi A, Fedi V, Fusi V, Giorgi C, Paoletti P and Valtancoli B 1999 Carboxy and diphosphate ester hydrolysis by a dizinc complex with a new alcohol-pendant macrocycle Inorg. Chem. 384115

45. (a) Saki N and Akkaya E U 2004 Bifunctional catalysis of ester hydrolysis: Novel hydrolytic enzyme models based on xanthene framework. J. Mol. Catal. A 219 227; (b) Xia J, Shi Y B, Zhang Y, Miao Q and Tang W X 2003 Deprotonation of zinc(II)-water and zinc(II)alcohol and nucleophilicity of the resultant zinc(II) hydroxide and zinc(II) alkoxide in double-functionalized complexes: Theoretical studies on models for hydrolytic zinc enzymes Inorg. Chem. 4270

46. (a) Wilcox D E 1996 Binuclear metallohydrolases Chem. Rev. 96 2435; (b) Sillen L G and Martell A E 1971 In Stability constants of metal-ion complexes Vol. 25 (London: Royal Society of Chemistry) 